\title{
Impact of Graphic Organizers on Reading Comprehension of English Learners at
}

\section{Intermediate Level}

* Laraib Rahat, Lecturer

** Ghani Rahman, Assistant Professor (Corresponding Author)

*** Shahabullah, Lecturer

\begin{abstract}
The present study deals with the impact of graphic organizers (GOs) on reading comprehension of intermediate level English learners. The study specifically focused on the teaching of English drama through graphic organizers. The study also explored participants' perceptions about using these graphic organizers. A quasi-experimental design was used in this study. Forty intermediate level students participated in this study. The twenty students of the experimental group received the GOs treatment, while the twenty participants of the control group were taught through the traditional method. A pre-test and post-test were conducted from both groups to test the impact of participants' reading comprehension with five weeks' treatment. The collected data were analyzed through a t-test. A significant difference was observed in the mean score of both groups and results revealed that the use of GOs had a positive impact on the comprehension of the students. The semi-structured interviews analyzed qualitatively through themes and subthemes showed a positive perception towards the use of GOs. The graphic GOs could help in increasing reading comprehension as well in understanding the text structure with a positive perception of their use.
\end{abstract}

Keywords: Graphic Organizers, English, Reading Comprehension, EFL Learners

Introduction

Reading is commonly done for many purposes. It is done daily, in the form of newspapers, books, and advertisements, etc. Maximum reading improves our skill to comprehend the text we read. In a formal setting like a classroom, the academic texts are read for learning the subject(s) and not just a casual reading in leisure requiring an improved skill of reading on the part of the learners. The reading becomes especially difficult in the case of reading a foreign language. In a foreign or second language context, the cognition of reading materials becomes more important than other skills required of colleges and schools' students for their academic and professional success (Grabe, 1991). The overall goal of reading is not to remember most of the specific details but to have a good grasp of the main ideas and supporting ideas, and to relate those main ideas to background knowledge as appropriate (Jiang \& Grabe, 2007). The relevant information in the text demands quite proficient reading comprehension skills on the part of the learners for identifying the ideas and making connections between different ideas. This improved skill to recognize and connect ideas in a given text helps the learners to comprehend efficiently and so, instead of remembering the entire text, the readers can remember the main ideas and as a result, the readers can think about what they have read. Reading is the ability to understand the information in a text and interpret it appropriately. This ability to read the written materials and processing their meanings to the level of comprehending is reading comprehension (Grabe, 2003). Reading is the process of receiving and interpreting information encoded in language via the medium of print; "Comprehension occurs when the reader extracts and integrates various information from the text and combines it with what is already known" (Jiang, \& Grabe, 2007).

* Women University Swabi Email: khanmarry236@gmail.com

** Department of English, Hazara University, Mansehra Email: ghani_saba@yahoo.com

*** Department of English, Kohat University of Science and Technology, Kohat

Email: shahabsahil6@gmail.com 
There are many strategies for the comprehension of the texts. One of these strategies is the use of GOs. The mean ideas are extracted automatically and the connections between them are built by good readers which are not done by less proficient readers (Chiang, 2005). GOs are visual representations of the information in the text (Jiang \& Grabe, 2007). They are visual and spatial displays designed to help us in learning and teaching of the material of a given text via special arrangements and lines for describing text and structure and the key conceptual relationships along with the context. Graphic organizers can be generic or specific. They can be versatile so that they can be used for similar text structures. However, some of them do not work with some texts. They can also be presented in many shapes and sizes (Grabe \& Stoller, 2001).

\section{Purpose of the Study}

It is commonly difficult for students to read with full comprehension of the texts written in foreign languages (English here). Being an academic need, the students try to comprehend the texts by using different strategies. These strategies are used by students on their own commonly. The reading in our academic environment is taught in an organized way with the help of tools. Although language tools have a great impact on improving the reading comprehension of students. GOs are one such type of tool and reading comprehension of the students can be improved to a great extent with the help of such tools. These GOs are either 'generic' or 'specific'. The primary goal of the current study was to investigate the impacts of graphic organizers on EFL learners' reading comprehension. This study was conducted for the two purposes. First, it analyzed the impact of GOs on students' reading comprehension at the college level. The second purpose was to explore the students 'perception of using graphic organizers in learning English Dramas at the intermediate level.

\section{Research Questions}

The study has the following objectives:

1. To analyze the impact of GOs on students' reading comprehension at the intermediate level

2. To explore students' perceptions about using graphic organizers in English Dramas at the intermediate level

\section{Literature Review}

According to Heidarifard (2014), GOs are helping tools for teaching, have roots in Ausubel's theory (1960) of meaningful [language] learning which was further developed and advanced by other theorists. There are various types of GOs having different conventions for information, communication and so, these GOs are categorized in many ways. The terms flow charts, semantic maps, semantic organizers, and networking diagrams are also used for GOs (Chiang, 2005). The 4 basic organizers formats are:
a) Hierarchical/network tree
b) Conceptual/spider map
c) Sequential/fishbone map
d) Cyclical/cycle map

From the above organizers' formats, commonly used GOs are:

1) Descriptive or Thematic Map as a graphic organizer

2) Network tree as a graphic organizer

3) Spider map as a graphic organizer

4) Problem and solution map as a graphic organizer

5) Problem-solution outline as a graphic organizer

6) Sequential episodic map as a graphic organizer

7) Fishbone map as a graphic organizer

8) Comparative and contrastive map as a graphic organizer

9) The compare-contrast matrix as a graphic organizer

10) Continuum scale as a graphic organizer

11) Series of events chain as a graphic organizer

12) Cycle map as a graphic organizer

13) Human interaction outline as a graphic organizer

14) Story map as a graphic organizer

15) Semantic maps.).

16) Diagram as a graphic organizer

17) Venn diagram as a graphic organizer 
18) Character Map as a graphic organizer

19) Brainstorm Web as a graphic organizer

(Jiang \& Grabe, 2007).

The discourse structure of the texts is recognized in important ways by GOs. The use of GOs is the visual representation of information. Graphic organizers are useful in organizing information easier to learn and understand (Rostami, 2012). GOs are used for activities like before-reading activity, duringreading activity, and after-reading activity (Ozturk, 2012). According to Hall (1977), GOs are also used as after reading activities and so, providing the format for review and summary of the given information in the text. GOs are both students' generated and teachers' generated (Ozturk, 2012). GOs promote the comprehension of students by relating the old information with the new information available in the texts (Tang, 1992). Chiang (2005) showed the effectiveness of GOs on reading comprehension and language learning attitudes of the students by constructing their GOs and cooperating within groups. Mede (2010) reported the positive impact of GOs on the efficiency of English reading and the positive attitude of students about GOs. They were also considered good for low-grade level readers than other post-reading strategies (Biria \& Muhammad, 2013). Similarly, the use of GOs' had a positive impact on students' reading comprehension in their L2 reading (Heidarifard, 2014; Hashemian, Bashir \& Sahar, 2014). All the theories supporting the use of GOs are based on the cognitive side of learning focusing on learners and explaining language learning from the perspective of cognitive structures, representations, and processes involved. The cognitive make-up of the students brought to the classroom is vital in the context of learning. The students' previous knowledge, motivation, learning strategies, and experience are crucial for proficiency in language learning (Anderson \& Pearson, 1984; Chiang, 2005).

\section{Research Methodology}

The study analyzed the impact of the GOs on students reading comprehension and their perceptions about GOs. The data collected was analyzed both quantitatively and qualitatively. The former helped the researchers to determine the effects of using Graphic organizers on English reading comprehension of students as a strategy, while the latter helped us to determine the perceptions of the students about GOs. A quasi-experimental design was used in the study where the students were divided into two groups. One of the groups was the control group, while the second group was an experimental group. The five weeks of treatment (teaching English dramas with the help of GOs) was given only to the experimental group and the control group was taught through the traditional method. The two dramas selected were the dramas included in the textbooks of the Khyber Pakhtunkhwa textbook board. These dramas were 'King Lear' and 'The Merchant of Venice' by William Shakespeare. These dramas were taught to the experimental group through GOs and the control group was taught through the traditional method. The data was collected through the instrument of a proficiency test. A pre-test was taken before the treatment and a post-test after the treatment. A sample of forty students through a convenience sampling procedure was selected from a public college in Shinkiari, Mansehra. The level of the students was intermediate level and all the students were female students. Both these groups had twenty students each. The units in the selected textbook contained reading comprehension activities, which were taught to students by using GOs. Apart from the textbook, five graphic organizers suiting different reading activities were also used. These activities were:

1) Pre-Reading Activity

2) During-Reading Activity

3) Post-Reading Activity

To understand in-depth, the participants' experiences and perceptions of the experimental group, a face-to-face interview was adopted to gather further data about the interest of the students in the use of graphic organizers. The interview was a semi-structured interview to find out whether GOs had any positive impact on students English 'reading and learning processes.

Impact of Graphic Organizers

The pre-test helped the researchers to check the homogeneity of the groups. The score was calculated out of 100 score for the pre-test. The results of the pre-test of both groups are given below. 
Table 01: Results of pre-test

\begin{tabular}{llll}
\hline & $\begin{array}{l}\text { Mean of the } \\
\text { score }\end{array}$ & Variance among score & $\begin{array}{l}\text { Standard Deviation in the } \\
\text { score }\end{array}$ \\
\hline experimental group & 47.05 & 9.90 & 3.14 \\
control group & 47.25 & 10.28 & 3.02 \\
\hline
\end{tabular}

The mean scores in the table above are almost the same for both groups. The difference between their scores is not significant (47.25\% of the control group and $47.05 \%$ for the experimental group) suggesting that both the groups were homogeneous in terms of their proficiency in reading. The students in both groups had the same knowledge about the selected two dramas. The low scores for both highlight the low level of comprehension of reading the text and so, the students could not answer the questions easily. The standard deviation and variance in the score endorse the same points and the difference in the score was not significantly effective and the groups were homogenous in terms of their reading comprehension. The t-value for the pre-test was calculated to verify the difference or no difference further.

Table 02: $t$-value of scores in pre-test

\begin{tabular}{lll}
\hline $\mathrm{t}$-value & $\mathrm{p}$-value & critical value \\
\hline 0.90 & 0.05 & 1.68 \\
\hline
\end{tabular}

The t-value calculated (with p-value of 0.05 ) from the scores was 0.90 , which was less than the critical t-value 1.68 and so, the difference between the score of the control and experimental group was not significant. After the pre-test, the five weeks treatment (teaching English dramas with the help of GOs) was given only to the experimental group and the control group was taught through the traditional method. At the end of the treatment, a post-test was conducted. The mean scores of both groups were again calculated.

\section{Table 03: Results of post-test}

\begin{tabular}{llll}
\hline & Mean & Variance & Standard Deviation \\
\hline Control group & 53.3 & 5.01 & 2.23 \\
Experimental group & 72.95 & 9.25 & 3.04 \\
\hline
\end{tabular}

The mean score in the post-test for the experimental group (72.95\%) this time was greater than the mean score for the control group (53.3\%). The mean score for the control group was far less than the score for the experimental group. The score for the control group though has increased in the post-test suggesting that the students have learned a lot to improve their reading comprehension but this group has learned less than the experimental group. The treatment given to the students had a positive impact on students' reading comprehension. The statistic measurement (t-test values) showed the same results. The difference between the scores in the post-test was statistically confirmed too.

Table 04: $t$-value of scores in post-test

\begin{tabular}{lll}
\hline $\mathrm{t}$-value & $\mathrm{p}$-value & critical value \\
\hline 4.12 & 0.05 & 1.68
\end{tabular}

The t-value calculated (with p-value of 0.05) from the scores was 4.12, which was more than the critical t-value 1.68 and so, the difference between the control and experimental group was significant this time. The groups after the treatment through GOs were not homogeneous and the experimental group performed better by learning through GOs and so to improve their learning comprehension of English dramas. The results suggest that students learn easily with the help of GOs and GOs should be used as learning tools.

\section{Students' Perception of the Use of GOs}

Findings in this section are categorized under two themes. The first theme is regarding participants experience about use/effects of graphic organizers. It further consists of four subthemes: (a) Grasping main ideas (b) overcoming grammar difficulty (c) improving vocabulary learning (d) interesting activities. The second major theme concerned about the experience of using different types of graphic organizers (few types used in the study), also has the three subthemes: (a) Active thinking when used in the pre-reading stage (b) comprehending main events, characters of the story when used in duringreading stage (c) long-time memorization when used as sum up in post-reading stage. Analysis of the interview data indicated that four subthemes have emerged under the theme of learning experience. The subthemes were (a) Grasping main ideas (b) overcoming grammar difficulty (c) Improving vocabulary learning and (d) interesting activities. Respondents were of the view that they had never used graphic organizers before. They also claimed that they had used graphic organizers first time as a 
reading strategy in any class. All the respondents told that the pre, during and post-reading activities were extremely effective in English class. By using graphic organizers they were able to grasp the main ideas of the text and they learned vocabulary. They worked in groups during each activity on graphic organizers which was very helpful for active thinking. The student also reported that some $G O s$ were difficult to construct without the guidance of the teacher.

All the respondents $(100 \%)$ from the group agreed that graphic organizers helped pick the main ideas. They informed that GOs were useful in comprehending the gist of a text. Many participants found it extremely interesting activity during the learning process.

R18: When it was first used in the class, I found it quite helpful to grasp the main ideas in the Play. R14: It was quite beneficial for getting the gist of the text .......

The participants pointed out that the effects of graphic organizers made the comprehension of the story easy event by event and character by character. Along with this, many respondents from the group pointed out that the graphic representation reduces the grammatical features in EFL reading by omitting unimportant parts of the text.

R13: We found ourselves very relax by using GOs for remembering all events and main characters...

R16: While learning through GOs, we were able to understand and memorize the main events, characters, climax, and the problem and solution of these two plays...

R08: GOs omit things like grammar and many difficult words...

R04: Grammar is always a boring part and by using GOs learned themes and characterization of a play in a relaxed manner.

The participants also considered GOs helpful for learning vocabulary. They also considered these activities very interesting to learn with ease. Using graphic organizers was helpful to grasp the main ideas and the structure of the text. GOs also helped them to learn important vocabulary. Grammar has been a great issue while learning; students liked graphic organizers because they omitted difficult parts of grammar. Students also had the view that using graphic organizers was like interestingly playing games. But one of the students also said that it was time-consuming.

R03: It is easy while learning with graphic organizers. One doesn't need to memorize chunks of conversational vocabulary.

R17: We recognize the meaning by inferring when we come to know the story event by event.

When asked about using GOs as pre-reading activity tools, $30 \%$ of students were in favor of using GOs. These students had the view that by using GOs as pre-reading activity tools, students were able to look at the title and the pictures of each Play to predict the content of the story. Following this procedure, students brainstormed possible key ideas contained in the text. These key ideas were very helpful when written on graphic organizers (brainstorming GO) and categorized by teachers onboard into groups. Seventy percent of students had the view that the use of graphic organizers (Event-chain and character map) as a during-reading activity helped them to understand the text in a much better way than they learned before that treatment. Hundred percent of students had the perception of using graphic organizers (story map and tree diagram) as a post-reading activity that it helped them a lot to memorize events and characters naturally than rote, which helped them to better perform in the posttest. However, the use of certain types of graphic organizers was not without some disadvantages and difficulties. Some respondents found that mapping on, consumed too much time, whereas few others found the time spent worth the effort. The major reason why graphic organizers were more helpful in promoting reading comprehension was that the participants needed to understand the text during reading. As a result, using graphic organizers as a reading/learning strategy in the pre-reading stage was more beneficial to the learners (Barron \& Schwartz, 1984).

R7: After taking instruction about GO especially when introduced as a pre-reading, I was attracted to listen and learn actively.

R12: These types of graphic organizers taught us to make guesses from contextual clues......

More than half of the students $(70 \%)$ stated that it was difficult when they were taught with the traditional method. The teacher gave them everything and they received passively and were asked to memorize that. While using GOs, especially, during-reading stage forced them to use their mind and thoughts which promoted better comprehension of the text. It also helped them to concentrate during reading thereby understanding sequences of events and traits of the characters in a better way. Thus, the activities interestingly promoted better comprehension and an environment of cooperation 
amongst the learners developed making that task more manageable.

R7: $\quad$ There were lots of idiomatic expressions. It seemed difficult when you first saw it. But it became easy after we took the pen and paper to note down the main events and characters' traits, when we tried to fill in a graphic organizer which were provided by the teacher.

R8: We discussed the characters' traits and events together so that we should not skip even any minor event or trait from the text.

The third subtheme extracted from the use of graphic organizers was their ability to promote active thinking, as reported by all 10 respondents (50\%). Even at the first stage of this study, then teacher-generated graphic organizers were used, in which they did not need to think actively. But when they were asked to construct their graphic map, they tend to think actively and were fully engaged in reading with proper concentration.

R15: At the end of the lesson, the teacher provided us with story map graphic organizers. We filled the boxes according to the question asked in those graphic organizers...it helped us to remember important main things as a summary of the lesson we read. I still remember all of the events sequences, characters, and all the main things mentioned in those plays.

R16: When we used graphic organizers at the end of the lesson, we mostly did remember all the events, characters, problems, and solutions in the story. We did not need to revise the whole text. We just had to look at the story map only, it would cover the main things in the whole play.

Apart from the effects of using graphic organizers in English, most of the students had the view that they would use graphic organizers in their other subjects also, especially, in their science subjects. The view of one of the students is under.

$\mathrm{R}$ : I I found using graphic organizers very interesting and beneficial. I would use that strategy in my other subjects also, especially in my science subject. It was like playing a game, and it was fun.

The respondents' overall experiences toward the use of graphic organizers in an EFL reading class were positive, although few students had the view that it was difficult and time consuming to use graphic organizers in English class, but the majority of the students appreciated the use of graphic organizers while teaching English, especially, dramas.

\section{Discussion}

The mean score in the post-test for the experimental group was greater than the mean score for the control group suggesting that GOs use as reading strategies had a positive impact on students' English reading comprehension. The mean score for the control group was far less than the score for the experimental group. The score for the control group though has increased in the post-test suggesting that the students had learned a lot to improve their reading comprehension but this group has learned less than the experimental group. The treatment given to the students had a positive impact on students' reading comprehension. The statistic measurement (t-test values) showed the same results. The difference between the scores in the post-test was statistically confirmed too. The t-value calculated was more than the critical t-value and so, the difference between the control and experimental group was significant in the post-test. The groups after the treatment through GOs were not homogeneous and the experimental group performed better by learning through GOs and so to improve their learning comprehension of English dramas. The results suggested that students learned easily with the help of GOs and GOs should be used as learning tools. Both the students generated and teachers generated GOs had a positive impact. The findings of the results confirmed that when new information was linked to the 'cognitive structure' of the learners, the information is acquired easily (Ausubel, 1960) being consistent with schema theory (Anderson \& Pearson, 1984). The GOs' role was found out from pre-reading to during-reading activity and even in post-reading activity (Heidarifard, 2014).

The results also indicated the perception of the students about using graphic organizers as a reading strategy. By representing main ideas in an organized manner and omitting the least important information in a text, graphic organizers help to make a text more comprehensible (Tang, 1992). The participants expressed their view that using GOs were more effective. Especially, graphic organizers when used in the during-reading stage, were more helpful in promoting reading comprehension in a better way. Studies have pointed out that students learn in a rather passive way when students learn without the use of graphic organizers. When learners are required to construct their graphic 
organizers, it promotes batter comprehension as learners are forced to get involved in the reading process more actively. Consequently, the results are more beneficial to the learners (Barron \& Schwartz, 1984). The GOs as learning tools had a more positive impact especially when the students used graphic organizers in the during-reading stage.

\section{Conclusion}

The primary aim of the present study was to analyze and confirm the impact of GOs on students' English reading comprehension. The study also determined the perceptions of students about GOs. The results analyzed revealed that GOs had a positive impact on students' English reading comprehension. The students could be trained in the use of GOs as learning tools. Some GOs like tree diagrams and brainstorming were found out quite helpful as pre-reading activity. Some other GOs like Event-chain and character maps were found out quite helpful as during-reading activity, while story maps and thematic maps were found out quite helpful as post-reading activity. The graphic organizers helped pick the main ideas by comprehending the gist of a text. The students considered the use of GOs extremely interesting, particularly, when they reduced the grammatical features in EFL reading by omitting unimportant part of the text along with their helpfulness in learning vocabulary with ease like interestingly playing games. During the pre-reading activity, the brainstorming GO for the prediction of the content of the story was favored. Event-chain and character map GO as a duringreading helped them understand the text in a much better way. The story map and tree diagram as post-reading activities helped them a lot in memorizing events and characters. GOs promote active thinking and when the students were asked to construct their graphic maps, they thought actively and were fully engaged in the reading with proper concentration. However, the use of certain types of graphic organizers was not without some disadvantages and difficulties. Some respondents found that mapping on, consumed too much time, whereas few others found the time spent worth the effort.

\section{References}

Anderson, R. C., \& Pearson, P. D. (1984). A schema-theoretic view of basic processes in reading comprehension. Handbook of reading research, 1, 255-291.

Ausubel, D. P. (1960). The Use of Advance Organizers in Learning and Retention of Meaningful Material. Journal of Educational Psychology, 51, 267-272.

Barron, R. F. (1969). The use of vocabulary as an advance organizer. In H. L. Herber, \& P. L. Sanders (Eds.), Research in reading in content areas: First-year report (pp. 29-39). Syracuse, NY: Syracuse University, Reading and Language Arts Center.

Barron, R. F., \& Schwartz, R. M. (1984). Graphic post organizers: A spatial learning strategy. In D. Charles, D. Holley and F. Dansereau, Spatial learning strategies (pp. 275-289). Cambridge: Academic Press.

Biria, R., \& Sharifi, M. M. (2013). Graphic organizers and reading comprehension ability: Evidence from Iranian EFL university students. Sino-US English Teaching, 10(5), 358-365.

Chiang, C. (2005). The effects of graphic organizers on Taiwnese tertiary students' EFL reading comprehension and attitudes towards reading in English. (Unpublished doctoral dissertation). Australian Catholic University, Urban, Australia.

Grabe, W. (2003). Using discourse patterns to improve reading comprehension. In JALT2002 at Shizuoka Conference Proceedings (pp. 9-16).

Hall, C. K. (1977). The effects of graphic advance organizers and schematic cognitive mapping organizers upon the comprehension of ninth-grade students. (Unpublished Master's Thesis). The State University of New Jersey, Rutgers.

Heidarifard, M. (2014). The effect of graphic organizers on 12 learners' reading comprehension. Journal of American Science, 10(3), 62-72.

Jiang, X., \& Grabe, W. (2007). Graphic organizers in reading instruction: Research findings and issues. Reading in a Foreign Language, 19, 34-55.

Mede, E. (2010). The effects of instruction of graphic organizers in terms of students' attitudes towards reading in English. Procedia-Social and Behavioral Sciences, 2(2), 322-325.

Öztürk, Ö. (2012). The effects of graphic organizers on reading comprehension achievement of EFL learners. Pamukkale University, 32, 37-45.

Rostami S. Z. (2012). The effect of graphic organizer and marginal L2 glossing training on the reading comprehension of ESP students. Researcher, 4 (4), 16-23.

Tang, G. (1992). The effect of graphic representation of knowledge structures on ESL reading comprehension. Studies in Second Language Acquisition, 14(2), 177-195. 